\title{
HYBRID SOCIAL MEDIA: EMPLOYEES' USE OF A BOUNDARY-SPANNING TECHNOLOGY
}

\author{
Chris Archer-Brown1 \\ Falmouth University, AIR Building, Penryn Campus, Treliever Road, Penryn TR10 9FE
}

Ben Marder

Business School, University of Edinburgh, 29 Buccleuch Place, Edinburgh, EH8 9JS

Tom Calvard

Business School, University of Edinburgh, 29 Buccleuch Place, Edinburgh, EH8 9JS

Tina Kowalski

The York Management School, University of York, Freboys Lane, Heslington, York YO10 5GD

1Corresponding Author

\begin{abstract}
Improved employee collaboration and communication can be facilitated by social technologies that extend within and beyond organizations. These social technologies have increasingly come to be represented by social media sites, which are used to extend workplace relationships across personal and professional boundaries in a hybrid role. This presents opportunities and risks as those boundaries are collapsed. Using boundary management as a theoretical lens, we evaluate the associations of relationship initiation between colleagues at different levels of organisations with employees' strategies and their well-being. We also investigate relationships with social media usage, age and propensity to self-monitor and group employees using cluster analysis. We consider implications of our findings for developing more sophisticated policies, training, and guidance for employees on the use of social media as a workplace tool.
\end{abstract}

Keywords: Social media; boundary management; well-being; cluster analysis; workplace relationships; employee collaboration; professional networks; work-life; multiple audiences. 


\section{Introduction}

Early attention in social media research focused on personal perspectives (e.g. boyd and Ellison, 2008) and considered social media in the workplace to be a distraction (Coker, 2011). Recently, researchers have considered the adoption of social media in an enterprise context (Leonardi et al., 2013; von Krogh, 2012) where benefits are derived as a result of transcending organisations structures (Chui et al., 2012). However, implicit in much social media research has been the assumption of separate personal vs. professional or internal vs. external boundaries; whereas the reality would arguably be better described in terms of coexisting, overlapping personal and professional networks, and therefore to conceptualize social media purely along an inside - outside organizational continuum is problematic.

To manage their social boundaries, users may resort to various strategies involving multiple profiles for targeted audiences, or presenting content that conforms to expectations of certain audiences (Hogan, 2010; Stutzman and Hartzog, 2012). Figure 1 summarises this perspective, indicating how the overlapping nature of social media sites challenge traditional boundaries for employees; with a spectrum from purely personal platforms to the left and purely professional ones to the right. In the middle, we describe those that span both domains as Hybrid Social Media (HSM) sites, which recognises an increasingly complex, multifaceted social media landscape, where it is necessary for employees to compartmentalize their digital footprint.

Managing what is visible in social media across different groups of acquaintances, friends and family members is fraught with complexity and risks (Sayah, 2013). In many cases users manage such 'context collapse' in the personal domain by conforming with the expectations of the most critical members of the user's personal relationship groups (Hogan, 2010; Marder et al, 2016). A teenager who is happy to connect with a grandparent on a well- 
managed Facebook profile might be less comfortable with the same relative following her Instagram or viewing a Snapchat story.

Conversely, constrained the rules and norms of interactions between employees in the same organisation, the recent advent of social technologies in the workplace provides opportunities to enhance professional relationships (Huang et al, 2015), develop social capital, share knowledge and collaborate more effectively (Leonardi et al, 2013). However, where social media connections span personal and professional domains, levels of anxiety have been noted to increase further (Karl \& Peluchette, 2011) where employers are the most likely to cause this effect (Marder et al, 2015).

\section{INSERT FIGURE 1 HERE}

Table 1 considers the distinctive boundary management issues facing employees using different platforms. HSM presents opportunities for communication and collaboration, but also presents the greatest risk of conflict and anxiety due to multiple boundary management challenges. HSM is therefore understood as a platform that has the potential to provide both professional and personal utility but which, paradoxically, presents the greatest risk of audience collapse with its consequent challenges. Consequently, employees may experience simultaneous positive and negative reactions on receiving a relationship initiation from colleagues, i.e. a friend or connection request. Consideration of boundary-spanning in social media must take account of employees' social and professional contexts and recognize that the issues presented are very different depending on the exact social network, platform, or site in question. 


\section{INSERT TABLE 1 HERE}

This paper responds to recent calls to understand the potential of social media as a workplace tool (Reynolds, 2015), and to investigate ways for employees to manage content that spans boundaries (Kane et al., 2014). Further it responds to calls to develop knowledge on the ways in which firms can exert control over the ways in which it can influence the use of social technologies and their effect on the visibility, persistence and editability of content, with a focus on platforms that span work and personal boundaries (Vaast \& Kaganer, 2013). Finally, it contributes to insight and theorisation of 'new', new technologies, especially pertaining to their tendency to create permeable boundaries (Howcroft \& Taylor, 2014).

This leads to our two research questions:

RQ1 To what extent does a hybrid social media users' response to friending by different levels within the organisation affect their chosen boundary management strategy?

$\mathrm{RQ}_{2}$ To what extent is it possible to predict or interpret boundary management choices through measurable characteristics or behaviours?

Below we review relevant scholarship on boundary theory and consequent boundarymanagement issues in social media. We then outline our hypotheses and study procedure, followed by a discussion of the results. Finally, we draw conclusions and consider the theoretical and practical implications for better understanding employees' use of social media in relation to their workplace, as well as providing discussion of broader issues such as policy development. 


\section{Boundary Management}

Boundaries are "mental fences" (Zerubavel 1991: 2) that separate organizations from their environment (Thompson, 1962), different projects or collaborations (Yeow, 2014), and identify internal groups of employees comprising hierarchies or functions (Balogun et al., 2005; Lindgren et al., 2008). While boundaries are set formally with suitable controls and practices, breaching them can often be positive in that it provides access to diverse resources (Aldrich and Herker, 1977; Aldrich, 1971).

Boundary-spanning employee roles and activities are thus critical in spreading flows of information and gaining access to resources outside of the organization (Tushman and Scanlan, 1981). This is particularly influential where peripheral members of groups challenge established norms (Davenport and Daellenbach, 2011). Through the development of social capital provided by bridging relationships (Edelman et al., 2004), such employees may be in a position to trade information and craft a position of leadership (Fleming and Waguespack, 2007). Multiple boundary spanning employees building cooperative links can thus enrich each other's work via these social ties (Adler and Kwon, 2002), through the voluntary sharing of knowledge (Kostova and Roth, 2003). Supporting and understanding boundary-spanning employees is therefore valuable to improving work processes (Aldrich and Herker, 1977). Social media platforms expand on these ideas by providing the potential for every employee to span boundaries and trade information (Gouillart, 2012). Where boundary-spanners were previously selected more exclusively for their sensitivity to social cues in multiple communities (Caldwell and O'Reilly, 1982), in an established public social media environment, the development of boundary management skills becomes more pressing for increasing numbers of employees.

Employees routinely segment their home and work lives (Fonner and Stache, 2011; Sayah, 2013), but social media "blur[s the] boundaries between work and social life" 
(Reynold, 2015: 152). This conflation of boundaries presents employees with the challenge of managing content associated with their online personas across multiple audiences

(Senarathne Tennakoon et al., 2013). Failure to do so can lead to employees losing status and even being fired (Holtgrewe, 2014; Schoneboom, 2011; Smith and Kannalley, 2010). One remedy is to avoid SM altogether in the workplace (Peluchette et al., 2013), although others suggest that professional networking sites (e.g. LinkedIn ${ }^{\mathrm{TM}}$ ) are more appropriate for employee use than their more social cousins (Kreps, 2009). Several prior studies have highlighted the generally problematic nature of the social extension of workplace relationships, especially where one party exerts authority over another (Frampton and Child, 2013; Karl and Peluchette, 2011; Vitak et al., 2012).

As technologically-supported boundary-spanners, employees are able to mitigate these risks in various ways: (1) by managing audiences, where, for example, a friend request may be rejected in Facebook while a connection in LinkedIn from the same person may be accepted; (2) by managing content, where privacy tools are employed to limit the visibility of content to friends of different user-directed categories; (3) by using a hybrid of the two previously mentioned strategies; or (4) by open boundary management, where neither content nor audiences are managed at all (Ollier-Malaterre et al., 2013).

However, each of these boundary management strategies presents its own challenges: causing offence by rejection or the anxiety of personal content that is not congruent with an employees' professional persona becoming visible to colleagues. Better understanding of how these dilemmas play out can help inform policies (Sánchez Abril et al., 2012).

\section{Conditions Affecting Boundary Management Behaviour}

We focus on employee boundary-management behaviour, specifically the choices on managing content and audiences. This has been noted to be an important factor in general 
understanding of behaviour on social media technologies (Kane et al., 2014). In order to investigate this important area of employee activity, we considered three separate but related areas: (1) initial responses to a work-related connection request; (2) characteristics of boundary-spanners and their decisions; and (3) patterns of boundary-spanning behaviours. These are outlined below

\section{Responses to Work Related Requests on Social Media}

Emotional responses to situations influence and are inseparable from decision-making or intentions to act (Izard, 1992); e.g. the blurring of boundaries by social media between work and home domains is associated with anxiety (Reynolds, 2015). Karl and Peluchette (2011) found that people experience both positive and negative emotions when receiving a friend request from an authority figure (in this case a professor relating to a student) and that decisions on whether to accept or reject were linked to these reactions. Such emotions can be experienced simultaneously and can affect related decisions (Cacioppo and Berntson, 1994). In this context, it is feasible that employees will experience a sense of opportunity and threat upon receiving a connection request from a senior colleague, who may provide enhanced access to information and other resources but whose judgement of the individual may be negatively affected by certain content. While we do not propose specific hypotheses about emotional reactions, we investigate here the general reported levels of employee well-being in order to provide an explanatory underpinning for general feelings about receiving and responding to different types of connection request, as a basis for the related, remaining questions of the research.

\section{Characteristics of Boundary-Spanners}

Certain employees have traditionally tended to be valued by leaders as a result of their ability to operate differently in environments that are subject to different norms (Caldwell and O'Reilly, 1982). However, social media empowers all employees with the potential to 
span internal and external boundaries relating to their working lives. The employee characteristics we investigate here therefore attempt to take into consideration both extant literature and this new working context.

Those using social media intensively in a personal context have been found to adopt many boundary-management behaviours across multiple domains or social settings (Ellison et al., 2007). High-intensity social media users are those for whom tools are embedded in their daily lives becoming the primary communication medium with friends (Ellison et al., 2007). Such increased use of information technology has been linked with use of advanced functions (e.g. complex privacy options), and is indicative of what separates experienced, sophisticated users from novices (Eastin and LaRose, 2000). The intensity of computer use leads to more positive attitudes toward its value and the increased sophistication of its use (Igbaria and Iivari, 1995). It has therefore been identified as an important factor for guiding the formulation of workplace social media policies (Panagiotopoulos, 2012). Thus, we expect more intensive social media usage to be associated with a greater awareness and use of these tools, leading to our first hypothesis.

H1 High-intensity social media using employees are more likely to employ boundary-management techniques compared to open boundary management.

Research into social media adoption in the US shows that the majority of the adult working population is registered with one or more social media platforms, with similar penetration across all age groups up to 50 (around 80\%) with only a minor drop off as retirement age is approached (65\%) (Pew Research, 2014). Research in the UK broadly mirrors this trend (Dutton and Blank, 2013). While intensity of use may be skewed towards younger users, the evidence suggests that older employees will be sufficiently familiar with 
social media protocols and norms such that they can take necessary actions to manage boundaries effectively. Older Facebook users may be more concerned about disclosing content across boundaries, whereas younger users disclose more extensively across a wider network of connections (Christofides et al., 2009, 2011; Chakraborty et al., 2013). Employee age is likely to be an important factor in workplace social media policies, given the potential communications from trade unions and other age-diverse stakeholders (Panagiotopoulos, 2012). Furthermore, waves of new technology like social media, in conjunction with demographic age trends in workforces, will inevitably come to influence boundary-spanning disclosure norms governing workplace relations (Holtgrewe, 2014). Given some available evidence that older employees have a greater concern for privacy and that younger generations might be more open in attitude, we propose the following hypothesis:

\section{$\mathbf{H} 2$ Older employees are more likely to utilise boundary-management techniques} compared to open boundary management.

Finally, we focus our attention on employees' tendencies towards self-monitoring; one of the key behaviours of effective boundary-spanners (Caldwell and O'Reilly, 1982). High self-monitors are defined as those who focus on self-presentation, pay attention to social cues in different contexts and moderate self-expression and behaviour as a result (Snyder, 1974). These types of behaviours are self-evidently consistent with tendencies to manage boundaries in social media, where the visibility of content is controlled subject to monitoring of the sensitivity of the norms and expectations of different audiences (Ollier-Malaterre et al., 2013). For employees to present a coherent and positive version of themselves online, selfmonitoring is needed for ensuring particular content reaches the right audiences across the 
appropriate boundaries (Hogan, 2010). Consequently, we expect an association between high self-monitors and their boundary-management strategies, leading to our final hypothesis:

H3 Employees who are high self-monitors will show greater use of boundarymanagement techniques in social media than those who are low self-monitors.

\section{Employee Boundary-Spanner Clusters}

While the identification of several relevant individual employee characteristics and responses is necessary to contribute to understanding of boundary theory in the context of HSM, the identification of groups of individuals, based upon characteristics, provides additional value in understanding any potential employee typologies (Wang and Hanges, 2011), and might guide social media policy and practice in relation to work. This third perspective on our study therefore seeks to identify employees in terms of user groups that are conceptually distinct. Prior theory has suggested the basic conceptualization of users that use open, content, audience, or hybrid types of boundary-management strategies (OllierMalaterre et al., 2013). However, empirical evidence of types of boundary-management strategies used and characteristics of individuals within such groups has thus far been lacking from work and employment research. We employ cluster analysis techniques to explore this phenomenon empirically.

\section{Method}

Our survey employed self-report measures that were derived from previously published studies (Appendix A); it was piloted with 15 professionals, who discuss any issues in order to confirm clarity of questions and reduce the risk of common method bias (Podsakoff et al., 
2003). All the scales used were found to have good reliability in terms of Cronbach's Alpha values above 0.7 .

Participants were first asked whether they had been sent a friend request from a superior, a colleague at the same level, and/or a subordinate. For each category, participants were: (1) asked to consider the most recent instance of one that was sent to them, and to articulate how they responded (accept with full access; accept with limited access; reject; or ignore); (2) were presented with measures for emotions from Warr's (1990) psychological well-being scale, using 8 items on a 6-point scale ('Never' - 'All the time'); (3) asked to report how often they felt these emotions in the days immediately following the work-related friend request.

We related our approach to testing the theoretical categorizations of boundarymanagement proposed by Ollier-Malaterre et al. (2013) as follows: open boundarymanagement $(\mathrm{OBM})$ was measured by the receiver reporting accepting a friendship request with full access to content. Acceptance with limited access to content (e.g. using groups, circles or other privacy tools) was noted as hybrid boundary management (HBM). Where the respondent ignored or rejected the friend request, we noted audience boundary management $(\mathrm{ABM})$. Observation of content boundary management $(\mathrm{CBM})$ is more difficult to ascertain as it relates to underlying intentions of employees to tailor idiosyncratic content to others at any given time, and we present evidence later to clarify this, but it was not measured separately in the survey. In addition, participants reported their organizational size, whether their employer had a social media policy, their age, gender and level of education.

In terms of the study sample, alumni who graduated from two UK business schools prior to 2013 were selected and were sent an email requesting that they complete an electronic survey that examined online social interactions in their workplace and a small donation (£0.50) was made to charity for each completed questionnaire. Both schools were 
part of Universities ranked in the UK Top 30, one based in the South of England and one based in Scotland. Recipients were also asked to forward the survey to their connections in full-time employment. Ultimately, data was collected from 641 participants, from whom 416 surveys were fully completed with usable data. Table 2 provides details on the background of the respondents.

\section{INSERT TABLE 2 HERE}

Some respondents reported on more than one friend request (590 observations from 416 respondents). We collected data from High School level of education upwards and found our data to be heavily skewed towards the upper end. While this is not surprising given the data collection method, we were careful not to draw any specific conclusions from this variable, particularly given that completion of university education may vary boundarymanagement decisions, but whether the respondent had completed an undergraduate degree or doctorate would be less likely to exhibit a meaningful difference. Subsequent analysis appeared to support this conclusion and the issue is highlighted in the limitations. Similarly, the majority of respondents were in full-time employment, rendering a poor predictor of conditions under which our hypotheses applied.

We evaluated our response types across these descriptive data, with particular interest in the distribution of the reported incidences of friendship requests. As expected, we noted a slight skew in distribution across age, where our younger respondents reported less requests from subordinates, and where our respondents in the 35-54 age range reported more. This was to be expected taking into account respondents' career stages. Those who worked in Finance and Education were slightly more likely to report friendship requests from superiors compared to other industries, which may reflect the hierarchical nature of the organisations, although our specific data allowed no more than speculation on the reason for this. In both 
cases the variation noted was minor and concluded to be unlikely to negatively affect the analyses.

\section{Results}

The results are presented in line with the three study aims outlined previously: (1) employees' emotional responses to relationship initiations in the form of types of friendrequest; (2) hypothesis testing to identify the extent to which certain employee characteristics relate to boundary-management decisions; and (3) exploration of conceptually distinct employee groups, based on the combined, profiled interaction of these characteristics.

\section{Employee Emotional Responses}

We expected the emotional responses to indicate that the experience of the event had had an impact on their well-being and in order to test this, we carried out one-sample t-tests finding that participants felt both negative and positive emotions $(p<.001)$, compared to the test value of 1 (no emotion). For the negative emotion, the effect size was medium, (Cohen's $d=.436)$, although much larger for the positive emotions measured $(d=.678)$. In general, however, given the restriction of range of responses at the low end of the scale, emotional responses were fairly modest (Appendix B)

A one-way MANCOVA was carried out to test the extent to which negative and positive emotions (DVs) differed based on the hierarchical position of the sender (IV). Gender, age, intensity of social media usage, organisation size, social media policy and education level were covariates. The results confirmed there was a significant overall difference in emotional responses by type of friend request $(\mathrm{p}<.001)$. Pairwise comparisons further showed that requests from superiors led to a higher negative response than both colleagues of the same level and subordinates $(p<.01)$. In addition, significantly greater 
positive emotions were felt when receiving a friend request from a peer compared to both superiors and subordinates (ps <.05) (Appendix C). Participants who held degrees felt significantly less emotion than those without $(\mathrm{p}<.05)$. Furthermore, older participants and those from larger organisations experienced less negative, high intensity emotions as a result of receiving a friend request $(p<.05)$.

Having confirmed some general, modest effects on employee well-being by workrelated friend request type or source, a multinomial logistic regression was used to test $\mathrm{H} 1$ $\mathrm{H} 3$, given the tripartite nature of the boundary management options and that the variables for these are nominal. The regression model was set up as follows: the DV reflected boundary management options (ABM, $\mathrm{n}=86 ; \mathrm{HBM}, \mathrm{n}=134$; OBM, $\mathrm{n}=370)$. The IVs, intensity, age and self-monitoring were drawn from extant literature. The following covariates were included in the model: negative and positive emotions; education level; presence of social media policy; and organizational size. OBM was used as the reference group, thus providing results for the predictor variables on $\mathrm{ABM}$ and $\mathrm{HBM}$ as compared to OBM.

\section{INSERT TABLE 3 HERE}

Overall the model was significant, indicating that the independent variables as a whole reliably distinguished between boundary-management behaviours (-2LL $=912.381, \chi 2$ $=66.495, \mathrm{p}<.001, \mathrm{df} .=16)$. Pseudo $R 2 \mathrm{~s}$ indicated a modest association between the prediction and the groupings (Nagelkerke's $R_{2}=.136$, Cox and Snell $R_{2}=.114$ ). Given the complex nature of boundary-spanning behaviour and that pseudo $R_{2}$ values are often conservative (Hosmer Jr and Lemeshow, 2004), a modest association here is perhaps unsurprising.

Significance of odds ratios (based on the Wald $\chi_{2}^{2}$ statistic) was assumed when $\mathrm{p}<$ .05. As suggested by Benaroch et al. (2006), to further increase confidence in the findings 
additional diagnostic tests were also carried out on the data, including the size of coefficients; confidence intervals (i.e. where $\mathrm{p}<.05$, the odds ratios did not cross 1 ); classification table; correlation between variables. The findings proved to be robust and the criteria of these tests were all satisfied.

\section{Hypotheses Testing}

H1 predicted that employees with a higher intensity had a greater likelihood to use boundarymanagement techniques compared to operating an open profile. There was a significant association, but in the opposite direction to that predicted. As shown in Table 3, social media intensity had a significant main effect within the model ( $\mathrm{p}<.01)$, but such that increased intensity relates to less use of $\mathrm{HBM}$ and $\mathrm{ABM}$ compared with OBM. The results show that an increase in intensity by one-point decreases the chance of having chosen ABM by $42 \%$ $(\operatorname{Exp}(\beta)=.581, \mathrm{p}=.001)$ and HBM by $24 \%(\operatorname{Exp}(\beta)=.764, \mathrm{p}=.046)$

$\mathrm{H} 2$ indicated our expectation that employee age was related to increased likelihood of the use of boundary-management techniques and was supported. Referring again to Table 3 , age had a significant main effect within the model $(\mathrm{p}<.05)$. The odds ratios were significant, for both $\operatorname{ABM}(\operatorname{Exp}(\beta)=1.604, p=.006)$ and $\operatorname{HBM}(\operatorname{Exp}(\beta)=1.339, \mathrm{p}=.044)$. An increase in age by one-point increases the chance of having chosen ABM by approximately two-thirds and HBM by a third.

$\mathrm{H} 3$ proposed that high self-monitors would be less likely to use OBM compared with ABM and HBM, but was rejected. Self-monitoring did not have a significant main effect within the model $(p=.398)$, indicating that boundary-management behaviours are unrelated to whether an employee reports being a high or low self-monitor.

Finally, the positive and negative emotion covariates were also both significant $(p<$ .01 ), showing that a reported one-unit increase in negative emotion doubles the chance of 
having chosen both $\mathrm{ABM}$ and $\mathrm{HBM}$ and halves in the case of increased positive emotions. Organisational size and social media policy were not significant predictors ( $p>.05)$. Educational level was significant overall $(\mathrm{p}<.05)$ within the model but not significant in predicting either DV individually ( $\mathrm{p}>.05)$.

\section{Employee Boundary-Spanning Clusters}

The purpose of our final phase of analysis was first to further investigate whether our independent variables could be used in clusters to explain boundary-management behaviours by groups of employees possessing multiple characteristics in combination.

We investigated a mix of categorical and continuous variables and adopting a twostep cluster analysis technique (Hair Jr et al. 1995). In line with Norusis (2008), we rejected the option of automated clustering (Milligan \& Cooper 1985), and followed the procedure proposed by Salvador and Chan (2004), designating the number of clusters manually, where findings may be further reinforced through adding and removing clusters around $k$.

Our analysis focused on our four main study variables; the two continuous variables of intensity and age, and the two categorical variables of self-monitoring (high/low) and boundary management behaviour (ABM, HBM, OBM). Given that we had already found self-monitoring not to be related to boundary-management choices, we assumed that both high and low self-monitors had reported carrying out each behaviour. High versus low selfmonitors crossed with the three employee boundary-management strategies meant that $a$ priori we might expect the existence of six potential clusters. While education had previously been found to be related to emotional response, the nature of our data made it unsuited to use in the cluster analysis (93\% university educated). In the cluster analysis, noise handling was applied at the default $25 \%$ level and based on trial-and-error. Taking into account the Silhouette measure of cohesion and separation, cluster sizes and ratios, seven clusters were 
found to be an optimal solution to the analysis, with the average Silhouette coefficient $=.04$, indicating that this represented a fairly good structure to fit to the data (Rousseeuw, 1987).

The analysis showed that choice of boundary-management behaviour clustered according to combinations of the three variables: self-monitoring, age and intensity. Out of these, self-monitoring was the strongest predictor of the clusters. The seven clusters (Table 4) were represented by four clusters of high self-monitors (C1, C2, C3, C4); and three of low self-monitors (C5, C6, C7).

\section{INSERT TABLE 4 HERE}

A MANOVA test examined significant differences between the clusters (DV: Age, Intensity; IV: Clusters), which was significant overall (Pillai's Trace $=.677, \mathrm{~F}=35.22$, df $=$ $14, p<.001)$. The subsequent pairwise comparisons supported differences in age and intensity among the clusters $(p<.05)$.

\section{INSERT FIGURE 2 HERE}

\section{Discussion}

Our findings show that many employees are more than capable of using different types of boundary-management behaviours to configure their social media networks in accordance with hierarchical and power-related workplace connections from different levels of an organization. Further, that several crucial personal characteristics or traits predicted the likelihood of boundary-management behaviours. In contrast with our expectations on intensity of technology use (Eastin and LaRose, 2000; Igbaria and Iivari, 1995), we found that the more intensively employees use social media, the less likely they are to opt for 
audience and hybrid modes of boundary-management relative to more open strategies. This implies that more experienced users can be relied upon to manage the sensitivities regarding different social norms and expectations when engaging with others in different groups more openly and flexibly, perhaps via careful monitoring and fine-tuning of content. Our evidence here is specifically about boundaries internal to organizations, but similar findings could be expected if tested using more external boundaries (Ollier-Malaterre et al. 2013).

Use of social technologies to communicate is often connected with millennials or Generation Y employees entering the workplace, so we tested the association of age to boundary-management, finding a positive result. Furthermore, we consistently found that emotional reactions to workplace friend requests reduced with increased age. In other words, while older colleagues are more inclined towards judicious online boundary-management in relation to work relationships, they may also experience less emotion over these dilemmas in general. This may be because they are more confident, simply care less about the medium, or for other reasons linking age to social technology that are worthy of further investigation.

In line with Caldwell and O'Reilly (1982), we expected a positive association between boundary-spanning and self-monitoring and the absence of such supports the notion that the reality is more complex. In other words, our data shows that, at a fairly general level, high self-monitors may engage in both open and restrictive boundary-management behaviour. That said, the cluster analysis indicated other factors working in combination with selfmonitoring: e.g. younger employees also lower in self-monitoring are more likely to operate more openly across boundaries on social media, suggesting a distinctive employee subgroup whose social media use may be risky. This creates a tension between organizations and their younger generations of employees, regarding the judicious suppression of content-sharing vs. the social and performance costs incurred by prohibiting freer flows of information (Mansell and Steinmueller, 2013). Conversely, older employees with lower levels of self-monitoring 
are more likely to manage content across multiple audiences if they are more experienced with social media. This indicates that age and experience moderate boundary-management behaviour among low self-monitors, further supporting the need to consider the role of age and experience in ongoing social media training and development initiatives.

High self-monitors who provide an open profile may be content managing, whereas the low self-monitors are possibly just unreservedly open with shared content. Furthermore, regarding high intensity users who do not limit content (HBM) or reject friend requests $(\mathrm{ABM})$, we can assume that they are actually content managing with open profiles. Although more research is needed to understand employees' immersion in online networks and boundaries, our findings provide an initial test of recent theory and conceptualizations of how personal and professional worlds collide on social media (Ollier-Malaterre et al., 2013), highlighting issues around employee boundary-management tendencies and work-life boundaries.

\section{Conclusions and Implications}

As social media is embedded in workplaces, relationships and communications, greater understanding of techniques employed by employees to balance the personal and professional risks and opportunities becomes increasingly important. Ollier-Malaterre et al. (2013) focus their attention on possibilities for greater sophistication in how workers manage these boundaries, proposing that content and hybrid strategies can bring greater overall respect and liking in the long-term for employees on social networks.

By empirically investigating these behaviours among working people, we highlight some limitations in the operationalization of the categories, namely that it is problematic to separate open and content boundary management, distinguishable only when there is knowledge of whether particular content was censored. We advocate the value of 
incorporating age, social media intensity and self-monitoring as important factors in determining and disentangling more nuanced forms of boundary-management behaviour. Different groups of employees may be adopting different styles, with implications for knowledge sharing, learning, and organizational cultures and subcultures forming around the technology.

While a focus on regulation, risk, and security entails suppressing over-sharing on social media, we suggest that this may inhibit the benefits that employees draw from this important resource on a daily basis. While our clusters indicate that a degree of boundary management may be required in very open, inexperienced employees, we also importantly find other clusters where employees could be encouraged to be more open and enjoy the benefits of reciprocal sharing and enriched social capital more fully.

We employed boundary-management, and by implication, boundary-spanning, as a theoretical lens with which to evaluate our data, arguing that social media profoundly shapes how employees define the boundaries of their work and organization and managing flows of resources in, out, and across those organizations. This is the first time employee boundarymanagement or spanning has been tested in relation to social media in this way and it has led to important conclusions that develop the narrative. Prior studies on social media audience management have tended to be amongst non-working populations or descriptive (Wilson, Gosling and Graham, 2012), whereas management research on boundary-spanning could be seen to have neglected technologically-supported forms of boundary activities (Marrone, 2010). Our sample and design brought together employees using social media with aspects of boundary theory, contributing to addressing both these limitations.

However, some limitations of this study itself should be acknowledged. First, we have highlighted the problematic nature of distinguishing open and content boundarymanagement behaviours and, while our findings shed some light on the conditions that allow 
us to propose a distinction between them, we are unable to robustly infer users' motivations and more specific actions over time. We suggest the need for further investigation, possibly of a qualitative nature, that will help to understand these activities in more detail. Second, our paper considers boundary-spanning issues in HSM but does not consider this from an inter-organizational perspective, which may prove to be an interesting area of future study at a different level of analysis. Our study reflects respondents' experiences on one particular platform which represents HSM. However, we recognise that the findings may be nuanced if tested in other platforms with their own norms and affordances (e.g. Google+, Twitter). While being encouraged by our initial conclusions about employee users, connections, and boundaries, we recognise the limits of generalizability and that HSM will benefit from further theorization and empirical study. Finally, we highlighted some limitations with the data related to the predominance of higher-educated, full-time employees in our sample. While this did not affect the analysis per se, it did limit the extent to which we could establish the conditions under which our proposed categorisation could be tested and future researchers may wish to consider different professions.

Similarly, future research may be focused on the direction of the boundary-spanning problem; our focus has been on the extent to which workplace relationships encroach on the personal identity of the individual. However, it may be equally the case that personal relationships can be positively or negatively affected by a different impression of a friend or family member where the professional façade which is normally invisible to them becomes apparent through social media. Given that self-monitors are characterised by their ability to adapt to different social situations, our findings may help develop that thinking.

Boundary-spanners have often been conceptualized as select individuals who are placed in roles sanctioned by authorities at work to cross the external extremes of a team or organization in order to act as a conduit for a range of resources (Aldrich and Herker, 1977; 
Aldrich, 1971; Thompson and Sinha, 2008). However, as social media becomes more prevalent both as a social tool (boyd and Ellison, 2008), a two-way consumer communications channel (Kietzmann et al., 2011), and way to enhance stakeholder collaborations (Majchrzak et al., 2013), we argue that it provides many more opportunities for employees to span working boundaries independently of any formal or monitored agendas.

Social media activities have previously been referred to as having internal and external uses, but we propose that such a neat organizational delineation in this fashion is no longer appropriate. Thus we propose that a new category of HSM be considered, concerning technologies that span personal, social, professional, and organizational boundaries.

Consequently, greater understanding of employees' approaches to this type of social media is required and our paper offers some initial insights that contribute to these developments. Recognizing the contradictions and mixed blessings of a technologically-supported ideology of openness (Gibbs et al., 2013), we offer empirical evidence of how employees as users, or users as employees, already manage these challenges themselves. Thus boundary-spanning theory can be refined and expanded into an online context, where every employee, rather than a select few in certain roles, has access to tools that allow them to cross inter- and intraorganizational boundaries.

Social technologies inside organizations have been widely accepted as a potential source of significant benefit in terms of collaborative knowledge generation and improved employee engagement (Davenport, Harris and Shapiro, 2010). Here, we argue that a more flexible, discretionary use of personal social media sites adds to this potential by enabling the social capital that exists in employees' many other networks across and beyond organizations. However, as reflected by some negative emotional responses in our well-being data, we recognize the risks of inappropriate use but believe these can be overcome through a 
policy-based approach co-created with groups of employees, encouraging optimal boundarymanagement techniques based on personal preferences and shared experiences in context. Furthermore, led by co-created policies, employees should be given adequate training and guidance on their social media usage, however this should not be approached as a top-down list of "do not's" but focussed on spreading the understanding that social media in the workplace can enhance workplace relations.

Boundary-spanners have historically been sanctioned by authorities in the firm and trained with self-monitoring behaviours that allow them to act appropriately in different social scenarios. Use of social networking platforms allows employees to take control of this process themselves, connecting with individuals from outside their own spheres both inside and outside the organization. Without a clear understanding of the risks of content that is not suitable for work being made visible outside in groups where different norms apply, the individual and the firm may be subject to reputational hazards. Conversely, some employees may be overly cautious by managing audiences or content too tightly, thereby closing off opportunities to network effectively and engage in reciprocal sharing practices that can add value. In many cases, a 'one-size-fits-all' social media policy will tend towards suppression of open-ness and may, in this way, be counter-productive to a proportion of the employees. By targeting policies and - particularly - training towards the groups we identify, firms can offer appropriate advice to the suitable groups. One possible way this could be put into operation is to create self-assessment questionnaires where users are able to establish their own propensity towards self-monitoring and social media use.

At the increasingly familiar extremes of social media use, crossing boundaries in controversial or unwelcome ways can be destructive, or conversely, excessive restriction of work-life boundaries may mean closing off opportunities to network effectively and engage in reciprocal sharing practices of considerable value. We believe our conclusions have 
important implications for helping understand how diverse employees use social media to manage work relationships and respond to the blurring of professional and personal boundaries.

\section{REFERENCES}

Adler, P. and S. Kwon (2002). 'Social capital: Prospects for a new concept', The Academy of Management Review, 27, pp. 17-40.

Aldrich, H. (1971). 'Organizational Boundaries and Inter-organizational Conflict', Human Relations, 24, pp. 279-293.

Aldrich, H. and D. Herker (1977). 'Boundary Spanning Roles and Organization Structure', The Academy of Management Review, 2, pp. 217-230.

Balogun, J., P. Gleadle., V.H. Hailey and H. Willmott (2005). 'Managing change across boundaries: Boundary-shaking practices', British Journal of Management, 16, pp. 261-278.

Benaroch, M., Y. Lichtenstein and K. Robinson (2006). 'Real Options in IT Risk Management: An Empirical Validation of Risk-Option Relationships', Management Information Systems Quarterly, 30, pp. 827-864.

Boyd, d. m. and N. B. Ellison (2008). 'Social network sites: Definition, history, and scholarship', Journal of Computer-Mediated Communication, 13, pp. 210-230.

Brandell, M. (2008). 'The new employee connection : Social networking behind the firewall.' Computerworld August 11, 2008

http://www.computerworld.com/s/article/print/322857/The_new_employee_connection_Soci al_networking_behind_the_firewall Accessed May 2015.

Cacioppo, J.T. and G.G. Berntson (1994). 'Relationships Between Attitudes and Evaluative Space: A Cricital Review, with Emphasis on the Separability of Positive and Negative Substrates', Psychological Bulletin, 115, pp. 401-423.

Caldwell, D.F. and C. A. O'Reilly (1982). 'Boundary spanning and individual performance: The impact of self-monitoring', Journal of Applied Psychology, 67, pp. 124-127.

Christofides, E., A. Muise and S. Desmarais (2011). 'Hey Mom, What's on Your Facebook? Comparing Facebook Disclosure and Privacy in Adolescents and Adults', Social Psychological and Personality Science, 3, pp. 48-54.

Christofides, E., A. Muise and S. Desmarais (2009). 'Information disclosure and control on Facebook: are they two sides of the same coin or two different processes?', CyberPsychology \& Behaviour, 12, pp. 341-5. 
Chui, M., Manyika, J., Bughin, J., Dobbs, R., Roxburgh, C., Sarrazin, H., Sands, G. \& Westergren, M. 2012. The Social Economy: Unlocking Value and Productivity through Social Technologies, McKinsey.

Coker, B. L. (2011). Freedom to surf: the positive effects of workplace Internet leisure browsing. New Technology, Work and Employment, 26(3), 238-247.

Davenport, S. and U. Daellenbach (2011). "“Belonging” to a Virtual Research Centre: Exploring the Influence of Social Capital Formation Processes on Member Identification in a Virtual Organization', British Journal of Management. 22, pp. 54-76.

Davenport, T.H., J. Harris and J. Shapiro (2010). 'Competing on talent analytics', Harvard Business Review, October, pp. 1-6.

Dutton, W.H. and G. Blank (2013). Cultures of the Internet : The Internet in Britain Oxford Internet Survey 2013 Report.

Eastin, M.S. and R. LaRose (2000). 'Internet Self-Efficacy and the Psychology of the DigitalDivide', Journal of Computer-Mediated Communication, 6.1

Edelman, L.F., M Bresnen., S. Newell., H. Scarbrough and J Swan (2004). 'The benefits and pitfalls of social capital: empirical evidence from two organisations in the UK', British Journal of Management, 15, pp. S59-S69.

Ellison, N.B., C Steinfield and C Lampe (2007). 'The Benefits of Facebook "Friends:" Social Capital and College Students' Use of Online Social Network Sites', Journal of ComputerMediated Communication, 12, pp.1143-1168.

Fleming, L. and D. Waguespack (2007). 'Brokerage, boundary spanning, and leadership in open innovation communities', Organization science, 18, pp. 165-180.

Frampton, B.D. and J. T. Child (2013). 'Friend or not to friend: Coworker Facebook friend requests as an application of communication privacy management theory', Computers in Human Behaviour, 29, pp. 2257-2264.

Fonner, K. L., \& Stache, L. C. (2012). All in a day's work, at home: teleworkers' management of micro role transitions and the work-home boundary. New Technology, Work and Employment, 27(3), 242-257.

Gibbs, J.L., N. A. Rozaidi and J. Eisenberg (2013). 'Overcoming the "Ideology of Openness": Probing the Affordances of Social Media for Organizational Knowledge Sharing', Journal of Computer-Mediated Communication, 19, pp. 102-120.

Gouillart, F. (2012). 'Co-Creation: The Real Social-Media Revolution', Harvard Business Review. Blog Network.

Hair Jr, J.F., R. E. Anderson, R. L. Tatham and W. C. Black (1995). Multivariate data analysis: with readings. Prentice-Hall, Inc. 
Hogan, B. (2010). 'The presentation of self in the age of social media: Distinguishing performances and exhibitions online', Bulletin of Science, Technology \& Society, 30, pp. 377386.

Holtgrewe, U. (2014). New new technologies: The future and the present of work in information and communication technology. New technology, work and employment, 29(1), 9-24.

Hosmer Jr, D. and S. Lemeshow (2004). Applied Logistic Regression. London: John Wiley \& Sons

Howcroft, D. and Taylor, P., 2014. 'Plus ca change, plus la meme chose?'-Researching and Theorising the 'new' new technologies. New Technology, Work and Employment, 29(1), pp.1-8.

Huang, Y., Singh, P.V. and Ghose, A., 2015. A structural model of employee behavioral dynamics in enterprise social media. Management Science, 61(12), pp.2825-2844.

Igbaria, M. and J. Iivari (1995). 'The effects of self-efficacy on computer usage', Omega, 23, pp. 587-605.

Izard, C.E. (1992). 'Basic emotions, relations among emotions, and emotion-cognition relations', Psychological Review, 99, pp. 561-5.

Kane, G., M. Alavi., G. Labianca and S. Borgatti (2014). 'What's Different About Social Media Networks? A Framework and Research Agenda', Management Information Systems Quarterly, 38, pp. 275-304.

Karl, K. A. and J. V. Peluchette (2011). "Friending” Professors, Parents and Bosses: A Facebook Connection Conundrum', Journal of Education for Business, 86, pp. 214-222.

Kietzmann, J.H., K. Hermkens., I.P. McCarthy and B.S. Silvestre (2011). 'Social media? Get serious! Understanding the functional building blocks of social media', Business Horizons, 54 , pp. 241-251.

Kostova, T. and K. Roth (2003). 'Social capital in multinational corporations and a micromacro model of its formation'. Academy of Management Review, 28, pp. 297-317.

Kreps, D. (2009). 'My social networking profile: copy, resemblance, or simulacrum? A poststructuralist interpretation of social information systems', European Journal of Information Systems, 19, pp. 104-115.

Leonardi, P.M.,. M Huysman and C. Steinfield (2013). 'Enterprise social media: Definition, history, and prospects for the study of social technologies in organizations', Journal of Computer-Mediated Communication, 19, pp. 1-19.

Lindgren, R., M. Andersson and O. Henfridsson, (2008). 'Multi-contextuality in boundaryspanning practices', Information Systems Journal, 18, pp. 641-661.

Lunden, I. (2014). Source: Facebook Is Building FB @Work, Techcrunch. 
Majchrzak, A., S. Faraj., G. C. Kane and B. Azad (2013). 'The Contradictory Influence of Social Media Affordances on Online Communal Knowledge Sharing', Journal of ComputerMediated Communication, 19, pp. 38-55.

Mansell, R. and W.E. Steinmueller (2013). 'Copyright infringement online: The case of the Digital Economy Act judicial review in the United Kingdom. New Media \& Society, 15, pp. $1312-1328$.

Marder, B., Joinson, A., Shankar, A. and Thirlaway, K., 2016. Strength matters: selfpresentation to the strongest audience rather than lowest common denominator when faced with multiple audiences in social network sites. Computers in Human Behavior, 61, pp.56-62.

Marder, B., Shankar, A., Houghton, D. \& Joinson, A. (2017). "What if my mum sees it?" Examination of visible brand interaction in the presence of a wider network. Information Technology \& People, 30(1), 210-226.

Marrone, J. (2010). 'Team boundary spanning: A multilevel review of past research and proposals for the future', Journal of Management, 36, pp. 911-940.

Marwick, A.E. and Boyd, D., 2011. I tweet honestly, I tweet passionately: Twitter users, context collapse, and the imagined audience. New media \& society, 13(1), pp.114-133.

Milligan, G. and M. Cooper (1985). 'An Examination of Procedures for Determining The Number of Clusters in a Data Set', Psychometrika, 50, pp. 159-179.

Norusis, M. (2008). NSPSS 16.0 Statistical Procedures Companion. London: Prentice-Hall Inc.

Ollier-Malaterre, A., N. P. Rothbard and J. M. Berg (2013). 'When Worlds Collide in Cyberspace: How Boundary Work in Online Social Networks Impacts Professional Relationships', Academy of Management Review, 38, pp. 645-669.

Panagiotopoulos, P. (2012). Towards unions 2.0: rethinking the audience of social media engagement. New Technology, Work and Employment, 27(3), 178-192.

Peluchette, J.V., K. Karl and J. Fertig (2013). 'A Facebook "friend" request from the boss: Too close for comfort?', Business Horizons, 56, pp. 291-300.

Pew Research., (2014). Social Networking Fact Sheet.

Podsakoff, P.M., S. B. MacKenzie., Y. J. Lee and N. P Podsakoff (2003). 'Common method biases in behavioural research: a critical review of the literature and recommended remedies', Journal of Applied Psychology, 88, pp. 879.

Reynolds, N. S. (2015). Making sense of new technology during organisational change. New Technology, Work and Employment, 30(2), 145-157.

Rousseeuw, P. (1987). 'Silhouettes: a graphical aid to the interpretation and validation of cluster analysis', Journal of Computational and Applied Mathematics, 20, pp. 53-65. 
Salvador, S. and P. Chan (2004). 'Determining the number of clusters/segments in hierarchical clustering/segmentation algorithms', Tools with Artificial Intelligence, ICTAI 2004. 16th IEEE Int.

Sánchez Abril, P., A. Levin and A. Del Riego (2012). 'Blurred Boundaries: Social Media Privacy and the Twenty-First-Century Employee', American Business Law Journal, 49, pp. 63-124.

Sayah, S., 2013. Managing work-life boundaries with information and communication technologies: the case of independent contractors. New Technology, Work and Employment, 28(3), pp.179-196.

Schoneboom, A. (2011). Sleeping giants? Fired workbloggers and labour organisation. New Technology, Work and Employment, 26(1), 17-28.

Schwabel, D. (2012). Millennials vs . Baby Boomers : Who Would You Rather Hire? Time. http://business.time.com/2012/03/29/millennials-vs-baby-boomers-who-would-you-ratherhire/print/ Accessed May 2015.

Senarathne Tennakoon, K. U. S., G. J. Da Silveira and D. G. Taras (2013). 'Drivers of context-specific ICT use across work and nonwork domains: A boundary theory perspective', Information and Organization, 23, pp. 107-128.

Smith, C. and C. Kannalley (2010). Fired Over Facebook: 13 Posts That Got People CANNED. Huffington Post.

Snyder, M. (1974). 'Self-monitoring of expressive behaviour', Journal of Personality and Social Psychology, 30, pp. 526-537.

Thompson, J. (1962). Organizations and Output Transactions. American Journal of Sociology, 68, pp. 309-324.

Thompson, S. and R Sinha (2008). 'Brand communities and new product adoption: The influence and limits of oppositional loyalty', Journal of Marketing, 72, pp. 65-80.

Vaast, E. and Kaganer, E., 2013. Social media affordances and governance in the workplace: An examination of organizational policies. Journal of Computer-Mediated Communication, 19(1), pp.78-101.

Wang, M. and Hanges, P.J. (2011). 'Latent class procedures: Applications to organizational research', Organizational Research Methods, 14, pp.24-31.

Wilson, R.E., S.D. Gosling and L.T. Graham. (2012). 'A review of Facebook research in the social sciences’, Perspectives on Psychological Science, 7, pp. 203-220.

Yeow, J. (2014). Boundary management in an ICT-enabled project-based organising context. New Technology, Work and Employment, 29(3), 237-252. 
Zerubavel, E. (1991). The fine line: Boundaries and distinctions in everyday life. New York: Free Press. 
Figure 1. Overlapping Social and Professional Spheres in Social Media

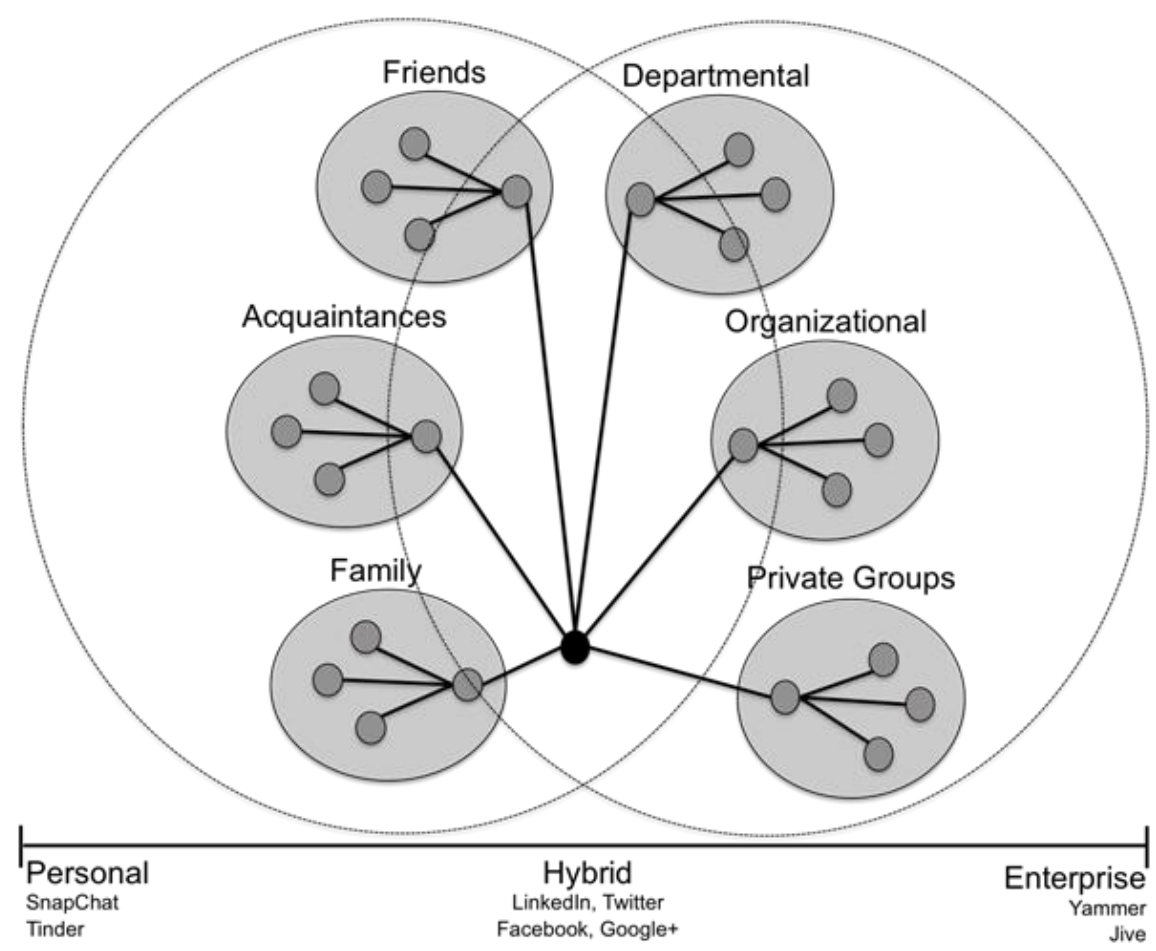


Table 1. Boundary-Management Issues in Social Media

\begin{tabular}{|c|c|c|c|c|c|c|}
\hline Category & Overall Purpose & $\begin{array}{l}\text { Platform } \\
\text { Examples }\end{array}$ & Audiences & Content & Boundaries & Boundary Management \\
\hline $\begin{array}{l}\text { Personal } \\
\text { Social Media } \\
\text { Public }\end{array}$ & $\begin{array}{l}\text { Development and } \\
\text { maintenance of } \\
\text { relationships and } \\
\text { enjoyment (boyd } \\
\text { and Ellison, 2008; } \\
\text { Joinson, 2008) }\end{array}$ & $\begin{array}{l}\text { Pinterest } \\
\text { Tumblr } \\
\text { Instagram } \\
\text { Snapchat }\end{array}$ & $\begin{array}{l}\text { Purely social, } \\
\text { enjoyment, fun }\end{array}$ & $\begin{array}{l}\text { Personal images and } \\
\text { observations, social } \\
\text { history }\end{array}$ & $\begin{array}{l}\text { Family / friends } \\
\text { Interest groups } \\
\text { Risk of conflict of self- } \\
\text { presentation between } \\
\text { multiple personal } \\
\text { audiences }\end{array}$ & $\begin{array}{l}\text { Boundary anxiety caused by } \\
\text { collapsing social contexts } \\
\text { (e.g. inappropriate social } \\
\text { content visible to family) if } \\
\text { connections are mismanaged }\end{array}$ \\
\hline $\begin{array}{l}\text { Enterprise } \\
\text { Social Media } \\
\text { Private }\end{array}$ & $\begin{array}{l}\text { Collaboration } \\
\text { between employees } \\
\text { and selected } \\
\text { partners or } \\
\text { customers } \\
\text { (Majchrzak et al., } \\
\text { 2013) }\end{array}$ & $\begin{array}{l}\text { Yammer } \\
\text { IBM Connections } \\
\text { Jive }\end{array}$ & $\begin{array}{l}\text { Colleagues and } \\
\text { partners } \\
\text { development of } \\
\text { human and social } \\
\text { capital }\end{array}$ & $\begin{array}{l}\text { Knowledge co-creation, } \\
\text { capture, codification and } \\
\text { distribution }\end{array}$ & $\begin{array}{l}\text { Colleagues } \\
\text { (Customers) } \\
\text { (Partners) } \\
\text { Low risk of conflict due } \\
\text { to consistent } \\
\text { presentation of } \\
\text { 'professional' self across } \\
\text { all groups }\end{array}$ & $\begin{array}{l}\text { Boundaries exist at the limits } \\
\text { of and within the firm but } \\
\text { present access to resources } \\
\text { not otherwise available. }\end{array}$ \\
\hline $\begin{array}{l}\text { Hybrid Social } \\
\text { Media } \\
\text { Public }\end{array}$ & $\begin{array}{l}\text { Multiple audiences } \\
\text { with a wide range } \\
\text { of familial, social } \\
\text { and professional } \\
\text { connections }\end{array}$ & $\begin{array}{l}\text { Facebook Google+ } \\
\text { LinkedIn } \\
\text { Twitter }\end{array}$ & $\begin{array}{l}\text { Extension of } \\
\text { workplace } \\
\text { relationships will } \\
\text { colleagues and } \\
\text { partners - social } \\
\text { dimension }\end{array}$ & $\begin{array}{l}\text { Mix of personal and } \\
\text { professional content } \\
\text { which brings resources } \\
\text { within reach of the } \\
\text { organization }\end{array}$ & $\begin{array}{l}\text { Heterogeneous } \\
\text { professional / social } \\
\text { connections } \\
\text { Greatest potential for } \\
\text { conflict due to mix of } \\
\text { social \& professional } \\
\text { self-presentation }\end{array}$ & $\begin{array}{l}\text { Multiple boundaries with } \\
\text { potential risks for } \\
\text { mismanagement of social / } \\
\text { professional contexts but } \\
\text { widest access to resources. }\end{array}$ \\
\hline
\end{tabular}


Table 2. Descriptive Data Table

\begin{tabular}{|c|c|c|c|c|c|}
\hline \multicolumn{2}{|c|}{ Gender } & \multicolumn{2}{|c|}{ Records } & \multicolumn{2}{|c|}{ Business Sector } \\
\hline Male & $46 \%$ & Subordinates & 113 & Finance & $16 \%$ \\
\hline Female & $54 \%$ & Peers & 314 & Education & $16 \%$ \\
\hline \multicolumn{2}{|c|}{ Age } & Superiors & 163 & Professional & $15 \%$ \\
\hline $18-24$ & $19 \%$ & \multicolumn{2}{|c|}{ Education } & Services & $8 \%$ \\
\hline $25-34$ & $47 \%$ & High School & $7 \%$ & Health & $7 \%$ \\
\hline $35-54$ & $30 \%$ & Undergrad & $33 \%$ & Retail & $5 \%$ \\
\hline $55+$ & $4 \%$ & Post-Grad & $52 \%$ & Others & $33 \%$ \\
\hline \multicolumn{2}{|c|}{ Role } & Doctorate & $8 \%$ & \multicolumn{2}{|c|}{ Revenue } \\
\hline Full Time & $85 \%$ & \multicolumn{2}{|c|}{ Policy } & $<\$ 10 \mathrm{~m}$ & $15 \%$ \\
\hline Part Time & $8 \%$ & In Place & $53 \%$ & $>\$ 10<\$ 1 b n$ & $22 \%$ \\
\hline Student & $6 \%$ & Not In Place & $35 \%$ & $>\$ 1 b n$ & $21 \%$ \\
\hline Retired & $1 \%$ & Unknown & $12 \%$ & Unknown & $31 \%$ \\
\hline
\end{tabular}

Table 3. Multinomial Logistic Regression of Employee Boundary-Management

\begin{tabular}{|c|c|c|c|c|}
\hline \multicolumn{3}{|c|}{ Main Effects $\left(\chi^{2}\right)($ sig. $)$} & \multirow{2}{*}{$\begin{array}{l}\mathbf{A B M}- \\
\text { OBM } \\
.581 * *\end{array}$} & \multirow{2}{*}{$\begin{array}{l}\text { HBM - } \\
\text { OBM } \\
.764^{*}\end{array}$} \\
\hline & & $\operatorname{Exp}(\beta)$ & & \\
\hline Intensity & $12.586^{* *}$ & Wald & 11.218 & 3.964 \\
\hline & & $p$ & .001 & .046 \\
\hline \multirow{3}{*}{ Self-Mon (Low) } & \multirow{3}{*}{$\begin{array}{l}1.842 \\
(.398)\end{array}$} & $\operatorname{Exp}(\beta)$ & .700 & .933 \\
\hline & & Wald & 1.825 & .101 \\
\hline & & $p$ & .177 & .751 \\
\hline \multirow{3}{*}{ Age } & \multirow{3}{*}{$\begin{array}{l}9.313 * * \\
(.009)\end{array}$} & $\operatorname{Exp}(\beta)$ & $1.604 * *$ & $1.339 *$ \\
\hline & & Wald & 7.608 & 4.054 \\
\hline & & $p$ & .006 & .044 \\
\hline \multirow{3}{*}{ Positive emotions } & \multirow{3}{*}{$\begin{array}{l}13.738 * * \\
(.000)\end{array}$} & $\operatorname{Exp}(\beta)$ & $.435 * *$ & $.578 * *$ \\
\hline & & Wald & 11.486 & 9.845 \\
\hline & & $p$ & .001 & .002 \\
\hline \multirow{3}{*}{ Negative emotions } & \multirow{3}{*}{$\begin{array}{l}9.382 * * \\
(.009)\end{array}$} & $\operatorname{Exp}(\beta)$ & $1.953 * *$ & $2.240 * *$ \\
\hline & & Wald & 7.648 & 10.371 \\
\hline & & $p$ & .006 & .001 \\
\hline \multirow{3}{*}{ Organisational size } & \multirow{3}{*}{$\begin{array}{l}1.921 \\
(.383)\end{array}$} & $\operatorname{Exp}(\beta)$ & 1.041 & .923 \\
\hline & & Wald & .214 & 1.284 \\
\hline & & $p$ & .644 & .257 \\
\hline \multirow{3}{*}{ Education level } & \multirow{3}{*}{$\begin{array}{l}6.943 * \\
(.031)\end{array}$} & $\operatorname{Exp}(\beta)$ & .255 & .388 \\
\hline & & Wald & 3.168 & 3.340 \\
\hline & & $p$ & .075 & .068 \\
\hline \multirow{3}{*}{ Social media policy } & \multirow{3}{*}{$\begin{array}{l}2.843 \\
(.241)\end{array}$} & $\operatorname{Exp}(\beta)$ & .665 & 1.057 \\
\hline & & Wald & 2.299 & .061 \\
\hline & & $p$ & .129 & .805 \\
\hline
\end{tabular}

**Significant at the 0.01 level. *Significant at the 0.05 level.

$\beta$ row: provides the logistic regression coefficient $\operatorname{Exp}(\beta)$, Wald row: provides the Wald $\chi^{2}$ stastistic, $p$ row: illustrates the significant value based on Wald $\chi^{2}$ statistic. Gender was used as a covariate but not shown, as it was non- significant. 
Table 4. Employee boundary-management cluster analysis results

\begin{tabular}{|c|c|c|c|c|c|}
\hline Cluster & Overall \% & Boundary-Management & Self-Mon & Age & Intensity \\
\hline $\mathbf{1}$ & $10.6 \%(\mathrm{n}=60)$ & Accept full access $(100 \%)$ & High (100\%) & 3.15 & 3.75 \\
\hline $\mathbf{2}$ & $20.6 \%(\mathrm{n}=117)$ & Accept full access (100\%) & High (100\%) & 4.38 & 3.21 \\
\hline $\mathbf{3}$ & $11.8 \%(\mathrm{n}=67)$ & Reject or ignore $(97 \%)$ & High (72\%) & 4.54 & 2.64 \\
\hline $\mathbf{4}$ & $11.5 \%(\mathrm{n}=65)$ & Accept but limit $(100 \%)$ & High (100\%) & 4.15 & 3.26 \\
\hline $\mathbf{5}$ & $13.6 \%(\mathrm{n}=77)$ & Accept but limit $(86 \%)$ & Low (100\%) & 4.45 & 2.98 \\
\hline $\mathbf{6}$ & $18.3 \%(\mathrm{n}=104)$ & Accept full access (100\%) & Low (100\%) & 4.43 & 2.72 \\
\hline $\mathbf{7}$ & $13.6 \%(\mathrm{n}=77)$ & Accept full access (90\%) & Low (100\%) & 3.71 & 3.93 \\
\hline
\end{tabular}

Results of the Two-Step cluster analysis tree results based on the clustering of boundary-management, selfmonitoring, age, social media intensity.

Figure 2. Cluster Analysis of Boundary-Management

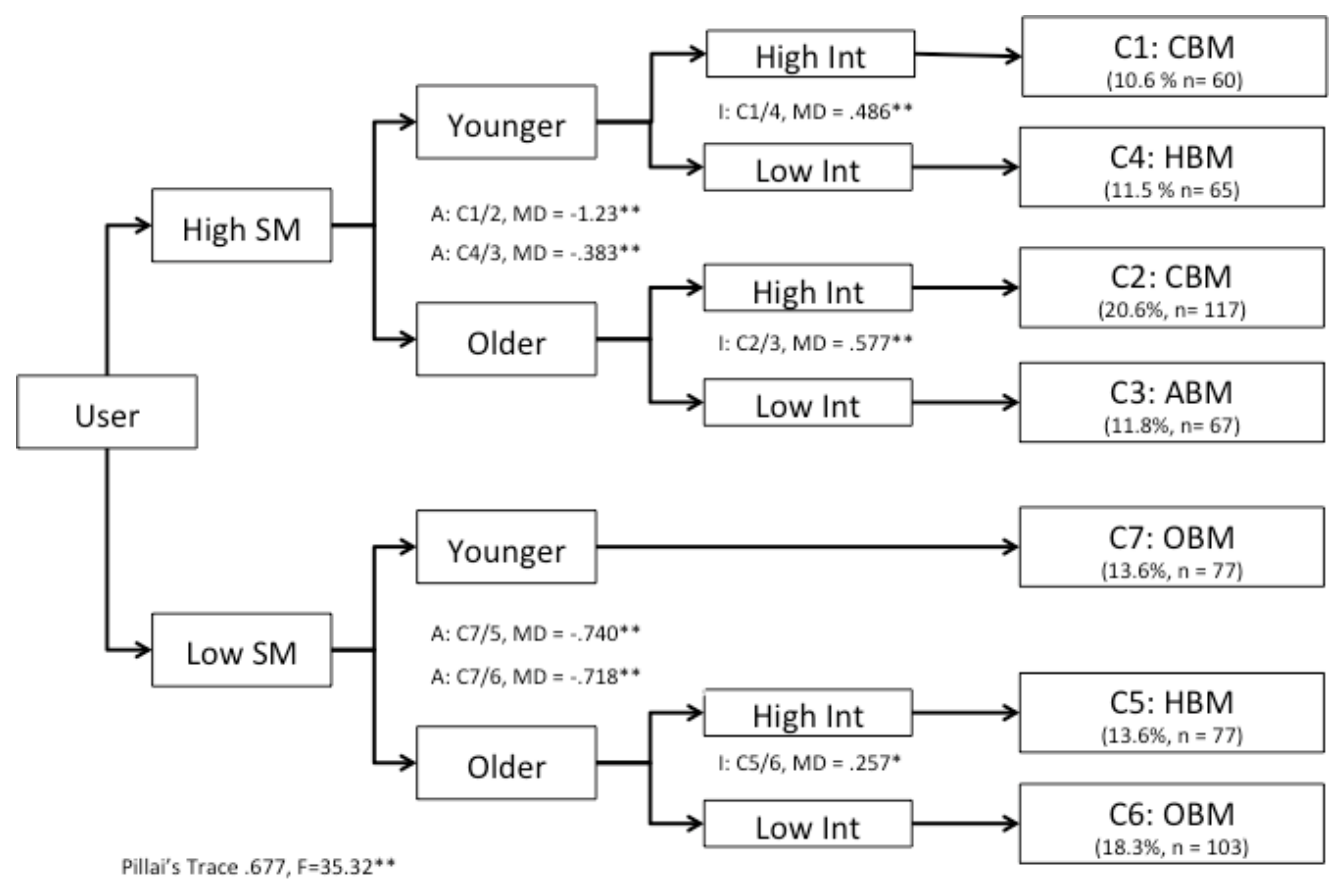

Two-Step cluster analysis tree results based on the clustering of boundary-management, self-monitoring, age, social media intensity. Mean differences are also illustrated deduced from pairwise comparisons of clusters based on age (A) and social media intensity (I) are also illustrated, $* *$ Significant at the 0.01 level. *Significant at the 0.05 level. 


\section{APPENDIX A}

\section{Measurement Scales}

\begin{tabular}{|c|c|}
\hline Measures & Items \\
\hline $\begin{array}{l}\text { High Intensity Emotions } \\
\text { Warr (1990) psychological well-being scale, 8- } \\
\text { items positive high intensity, 8-items negative } \\
\text { high intensity emotions, 6-point scale (Never - } \\
\text { All the time) ( } \alpha \text { s > 0.8) } \\
\text { Question: In the days immediately following your } \\
\text { decision to accept the friend request from the } \\
\text { superior/colleague of the same level/ subordinate } \\
\text { with full access, how often did the decision you } \\
\text { made make you feel the emotions given below. }\end{array}$ & $\begin{array}{l}\text { Negative high intensity emotion items: } \\
\text { 1) Alarmed } \\
\text { 2) Afraid } \\
\text { 3) Tense } \\
\text { 4) Aroused } \\
\text { 5) Anxious } \\
\text { 6) Uneasy } \\
\text { 7) Upset } \\
\text { 8) Discouraged } \\
\text { Positive high intensity emotion Items: } \\
\text { 1) Excited } \\
\text { 2) Energetic } \\
\text { 3) Enthusiastic } \\
\text { 4) Alert } \\
\text { 5) Cheerful } \\
\text { 6) Elated } \\
\text { 7) Glad } \\
\text { 8) Pleased }\end{array}$ \\
\hline $\begin{array}{l}\text { Social Media Intensity } \\
\text { Ellison et al's (2007) Social Media Intensity } \\
\text { (SMI) scale was used to measure the level } \\
\text { Facebook integrated into the lives of the } \\
\text { participants, this involves } 8 \text { items. Questions } 1-6 \\
\text { were measured along 5-point scales (Strongly } \\
\text { disagree - Strongly agree). Question } 7 \text { and } \\
\text { question } 8 \text { as suggested by Ellison et al (2007) } \\
\text { were measures using independent scales that were } \\
\text { then split into 20th percentiles to provide } 5 \\
\text { possible data points to be consistent with } \\
\text { questions 1-6. }(\alpha=0.79 \text { ) }\end{array}$ & $\begin{array}{l}\text { 1) Facebook is part of my everyday activity } \\
\text { 2) I am proud to tell people I'm on Facebook } \\
\text { 3) Facebook has become part of my daily routine } \\
\text { 4) I feel out of touch when I haven't logged onto } \\
\text { Facebook for a while } \\
\text { 5) I feel I am part of the Facebook community } \\
\text { 6) I would be sorry if Facebook shut down } \\
\text { 7) How long do you spend logged in on an } \\
\text { average Facebook session? } \\
\text { 8) Approximately to the nearest 20, how many } \\
\text { Facebook friends do you have? }\end{array}$ \\
\hline $\begin{array}{l}\text { Self-Monitoring } \\
\text { Self-monitoring was measured using a } 10 \text { item } \\
\text { scale (7+/3-) answered using a 5-point scale (Very } \\
\text { inaccurate - Very-accurate) derived from } \\
\text { (Snyder, 1974), by Goldberg et al (2006) as part } \\
\text { of their International Personality Item Pool. From } \\
\text { this a median split was employed to ascertain } \\
\text { high/low self-monitors in line with Snyder's } \\
\text { (1974) original conception. ( } \alpha=0.82) \\
\text { Question: How accurate are the following } \\
\text { statements at describing yourself. }\end{array}$ & $\begin{array}{l}\text { (+) } \\
\text { 1) Would make a good actor } \\
\text { 2) Put on a show to impress people } \\
\text { 3) Am likely to show off if I get the chance } \\
\text { 4) Am good at making impromptu speeches } \\
\text { 5) Like to attract attention } \\
\text { 6) Use flattery to get ahead } \\
\text { 7) Am the life of the party } \\
\text { (-) } \\
\text { 8) Hate being the center of attention } \\
\text { 9) Don't like to draw attention to myself } \\
\text { 10) Would not be a good comedian }\end{array}$ \\
\hline Demographics & Age, Gender, Education, Occupation, Industry. \\
\hline
\end{tabular}




\section{APPENDIX B}

Determination of Affective Emotion as a Result of a Friend Request

\begin{tabular}{|lccccccc|}
\hline \multicolumn{1}{|c}{ Emotion type } & $\begin{array}{c}\text { Mean } \\
\text { diff }\end{array}$ & $\boldsymbol{t}$ & $\boldsymbol{p}$ & s.d. & Low Cl & Upp Cl & $\begin{array}{c}\text { Cohen's } \\
\boldsymbol{d}\end{array}$ \\
\hline Negative High $(\mathrm{NH})$ & .230 & 10.604 & .000 & .528 & .190 & .270 & .436 \\
Positive High (PH) & .598 & 16.423 & .000 & .885 & .530 & .670 & .678 \\
\hline
\end{tabular}

\section{APPENDIX C}

Difference in Emotions Depending on Colleagues of Different Hierarchical Positions

\begin{tabular}{|lcccccc|}
\hline \multicolumn{1}{|c}{ Variable } & $\begin{array}{c}\text { Pillai's } \\
\text { Trace }\end{array}$ & $\mathbf{F}$ & $\boldsymbol{p}$ & df & Error df & $\begin{array}{c}\text { Partial - } \\
\text { eta }^{2}\end{array}$ \\
\hline Requester type & $.047^{* *}$ & 6.355 & .000 & 4 & 1066.00 & .023 \\
Intensity & .008 & 2.218 & .985 & 2 & 532.00 & .008 \\
Organisational size & $.016^{* *}$ & 4.222 & .015 & 2 & 532.00 & .016 \\
Education level & $.026^{* *}$ & 7.150 & .001 & 2 & 532.00 & .026 \\
Social media policy & .006 & 1.656 & .192 & 2 & 532.00 & .006 \\
Age & $.011^{*}$ & 3.022 & .049 & 2 & 532.00 & .011 \\
Gender & .002 & .535 & .586 & 2 & 532.00 & .002 \\
\hline
\end{tabular}

**Significant at the 0.01 level. *Significant at the 0.05 level. 